\title{
Relative Spatial Accuracy Evaluation of the Shuttle Radar Topography Mapping (SRTM15 + V2.0) Dataset on the Cameroon Continental Shelf
}

\author{
Jean Megope Foonde \\ Department of Geography, Northern Illinois University, DeKalb, Illinois, USA \\ Email: jpmefoo@gmail.com
}

How to cite this paper: Foonde, J.M. (2019) Relative Spatial Accuracy Evaluation of the Shuttle Radar Topography Mapping (SRTM15 + V2.0) Dataset on the Cameroon Continental Shelf. Open Access Library Journal, 6: e5656.

https://doi.org/10.4236/oalib.1105656

Received: July 31, 2019

Accepted: August 19, 2019

Published: August 22, 2019

Copyright $\odot 2019$ by author(s) and Open Access Library Inc.

This work is licensed under the Creative Commons Attribution International License (CC BY 4.0).

http://creativecommons.org/licenses/by/4.0/

\section{(c) (i) Open Access}

\begin{abstract}
This study presents a comparison between two bathymetric datasets covering the continental shelf of Cameroon. One of these datasets, Campus Cameroun, is based on a specific single-beam echosounder survey used in an authoritative study. The other is an excerpt of the SRTM15 + V2.0,-free and open Global Bathymetry and Elevation Data model which provides background information for Google Earth, Google Maps, etc.- - whose ocean bathymetry is based on a combination of satellite altimetry and echosounder data compiled from various sources. In the absence of multibeam bathymetric data for this area, this article assesses the local performance of the SRTM15 + V2.0 by evaluating its relative positional accuracy with the Campus Cameroun bathymetric dataset, its completeness and, therefore, determines its suitability for geomorphological studies.
\end{abstract}

\section{Subject Areas}

Earth Sciences

\section{Keywords}

Accuracy, Bathymetry, Campus Cameroun, Continental Shelf,

Error Distance, Global Terrain Model, Isobaths, Positional Accuracy,

Satellite Altimetry, SRTM15 + V2.0

\section{Introduction}

Bathymetry is important to the understanding of the ocean's hydrological, geological, and geophysical processes [1]. Unlike spot elevations which are assigned 
to position or features that are easily identifiable, water depth measurements are not benchmarked. This makes accuracy and precision of bottom elevations a constant concern and, consequently, a key requirement for ocean study, exploitation, and delimitation [2]-[8]. Despite the progress made in data collection and manipulation, bathymetry still suffers from problems due to instrumental, methodological, and human deficiencies resulting in inaccurate or imprecise representation. That is why scrutinizing bathymetric datasets and derived products (maps, 3D representation) is very important, as flaws can influence the outcome of any research and, if not evaluated or corrected, could nullify the results of a spatial analysis. From this perspective, what is the accuracy of SRTM15 + V2.0, a Global Bathymetry and Elevation Data model, on the Cameroon Continental PlateForme?

Maritime surveys are expensive. This certainly explains why Cameroon has conducted only two major scientific surveys on its maritime territory in its development efforts since 1960. The first goes back to 1962 [9]. Despite many imprecisions, it served as the basis for the few studies conducted on the maritime Cameroon until the nineties. The more recent, Campus Cameroun, a high-resolution and accuracy Single Beam Echo Sounders (SBES) survey, took place between 1990 and 1993. Its outcome was the edition in 1996 of the Carte sédimentologique du plateau continental du Cameroun [10] widely used since then. This lack of up-to-date and detailed data whose consequences are a low national scientific production relative to the oceanic environment -explains the interest of evaluating the other available data sources like SRTM15 + V2.0 as they may serve as reliable alternative.

SRTM15 + V2.0 is the latest (2019) of a stack of eponymous Global Terrain Models (GTM) that have gone through a series of improvements and enrichments since its inception. This evolution was in response to issues identified about its performance in shallow waters where features are discreet [11] [12] [13]. Particular concerns been raised in areas where high-quality bathymetry data were non-existent or unavailable as it's the case here.

To determine the suitability for use in geomorphological studies, this paper aims to assess the spatial accuracy of the SRTM15 + V2.0 for the Cameroon's continental shelf because-despite the tools and precautions used in their development-global DBMs are not error free [14]-[19]. To get the measure of these inaccuracies, various methodologies have been developed [20]. These methodologies all have a common element-they are based on the distance theorem. That is the reason the measure chosen for this evaluation is the error distance with Campus Cameroun. Obtained through GIS proximity tools, this error measurement will help quantify and qualify the relative positional accuracy of SRTM15 + V2.0.

\section{Study Area}

The area covered by this research is Cameroon's the $13,062 \mathrm{~km}^{2}$ continental 
shelf. It lies under the shallow water of the Bight of Bonny (Gulf of Guinea) in the east-central Atlantic Ocean. With the Cameroon Volcanic Line (CVL) as its center axis, this area is bounded between $2^{\circ} 20^{\prime} \mathrm{N}-4^{\circ} 40^{\prime} \mathrm{N}$ and $8^{\circ} 0^{\prime} \mathrm{E}-10^{\circ} 0^{\prime} \mathrm{E}$ in a S-NNW orientation (Figure 1).

With the bathymetric data available, it has been established in broad outlines that From the Rio del Rey area in the North-West to the Ntem outlet in the south, The Cameroon Continental Shelf displays a slightly variable topography where, from the shore to the break occurring here at around $-100 \mathrm{~m}$, the seafloor made of mud dominant sediment consist of a flat terrace with slope oscillating between $0.2 \%$ and $0.5 \%$.

\section{Related Works}

The accuracy of freely available GTM such as ASTER, GEODATA, SRTM stacks,

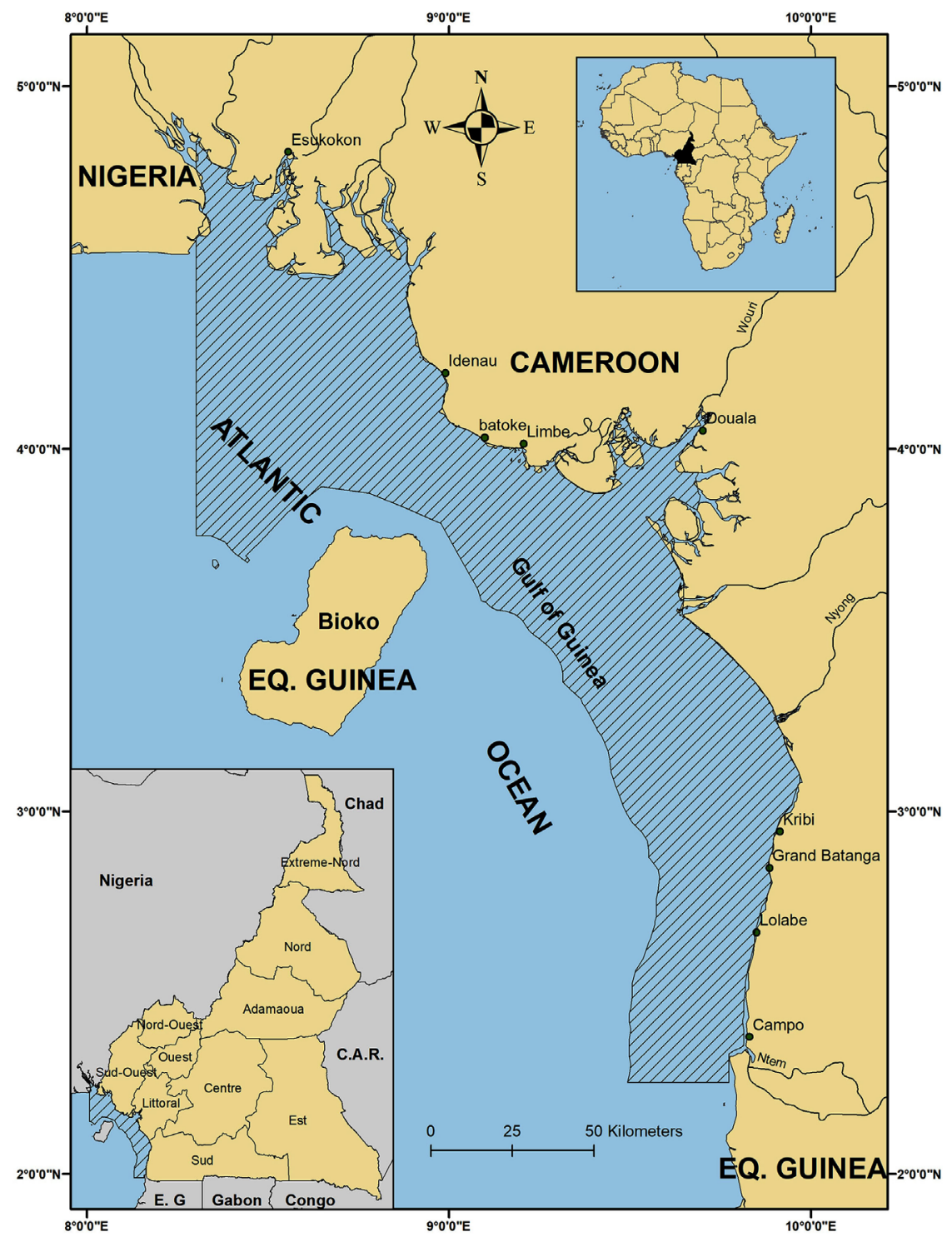

Figure 1. Study area. 
is a constant concern for the scientific community. All around the world research is conducted to evaluate their closeness [21] [22] [23] [24]. A review of literature reveals that most of these studies are focused on the vertical accuracy of the models on emerged territories or are comparison of their respective resolutions. This accuracy of the height measurements is established by reference to GPS control points or the geoid. The recent publication of Yap et al. [25] on Cameroon is part of this trend. This work credited SRTM 1 with a $13.25 \mathrm{~m}$ Root Mean Square error (RMSE) and $7.41 \mathrm{~m}$ Median Absolute vertical error distance over the landmass, a $15.12 \mathrm{~m}$ and $2.86 \mathrm{~m}$ RMSE and Median vertical error distance near water bodies. Although this research offers a strong insight, its results can't automatically (or without verification) be extended to the maritime domain data which collection responds to a different paradigm. Also, in contrast to the above-mentioned work, and due to the specificity of the area of interest, the evaluation of SRTM15 + V2.0 will not be based on a triangulation from the ground truth control points but rather on a comparison with Campus Cameroun a database acquired differently. This work constitutes the first genuine attempt to assess the bathymetric accuracy of SRTM15 + V2.0 for Cameroon.

\section{Data Sources}

The present study is based on a relative comparison of the SRTM15 + V2.0, a dataset from a world renown reference source of data derived from a compilation of satellites survey (SDB) and soundings (SBES) with a SBES dataset collected during the Campus Cameroun survey serving as "ground-truth".

\subsection{Campus Cameroun}

Efforts to chart Cameroon's waters go back to 1962, when the platform Ombango surveyed Cameroon's continental shelf. The bathymetric data collected during that expedition were used to draw the map known as Fonds de pêche le long des côtes de la République Fédérale du Cameroun [9]. Although-in comparison to the Cameroon Fernando-Po (5380) map based on bathymetric surveys published on old charts (S.H.M., 1910) - this 1964 map gave a valid general representation of the Cameroon continental shelf, it was plagued with numerous inaccuracies and imprecisions. These errors increase away from the coastline and the remarkable landmarks, especially when depths exceeded 50 meters. This lack of precision and vagueness was attributed to three deficiencies of the l'Ombango: the sonar which was a fish finder thus not suitable for mapping sampling; uneven navigational control (fuzzy road, inconsistency in vessel speed); incorrect positions (errors were likely to reach 2 miles) on the outer shelf especially due to the dead reckoning and the sextant positioning techniques used then, as well as the radial and diagonals spacing of the survey that leaves large areas not covered.

From 1990 to 1993, the Campus Cameroun survey was conducted on board of the R/V Andre Nizery with the goal to correct the 1964 map. For localization the Andre Nizery was equipped with a GPS receiver authorizing a \pm 80 metrical 
range accuracy (random error of a GPS system during 1990 era) [26]. During this exploration as bathometer, both a single beam Simrad EK 38 sounder and a seismic reflection SPARKER (100 - 1000 joules) device equipped with a graphic recorder 4600 - 3200 EPCI were used. Their vertical accuracy was typically \pm 1 $\mathrm{m}$. Following an itinerary and scientific recommendations established to maximize both coverage and efficiency, more than fifteen hundred bathymetric data (XYZ) were collected across the continental shelf of Cameroon following less spaced radials $(\approx 1.5 \mathrm{~km}$ ) and diagonals (Figure 2). Therefore, in comparison to the 1962 data, the Campus Cameroun survey was more densified and, the positioning more precise. The 1550 Campus Cameroun's datapoints used in this work are the same that were used for the Carte sédimentologique du plateau continental du Cameroun (1996), a set of three maps depicting isobaths with an equidistance of $10 \mathrm{~m}$. It is the most recent single-beam survey dataset of the study area [10].

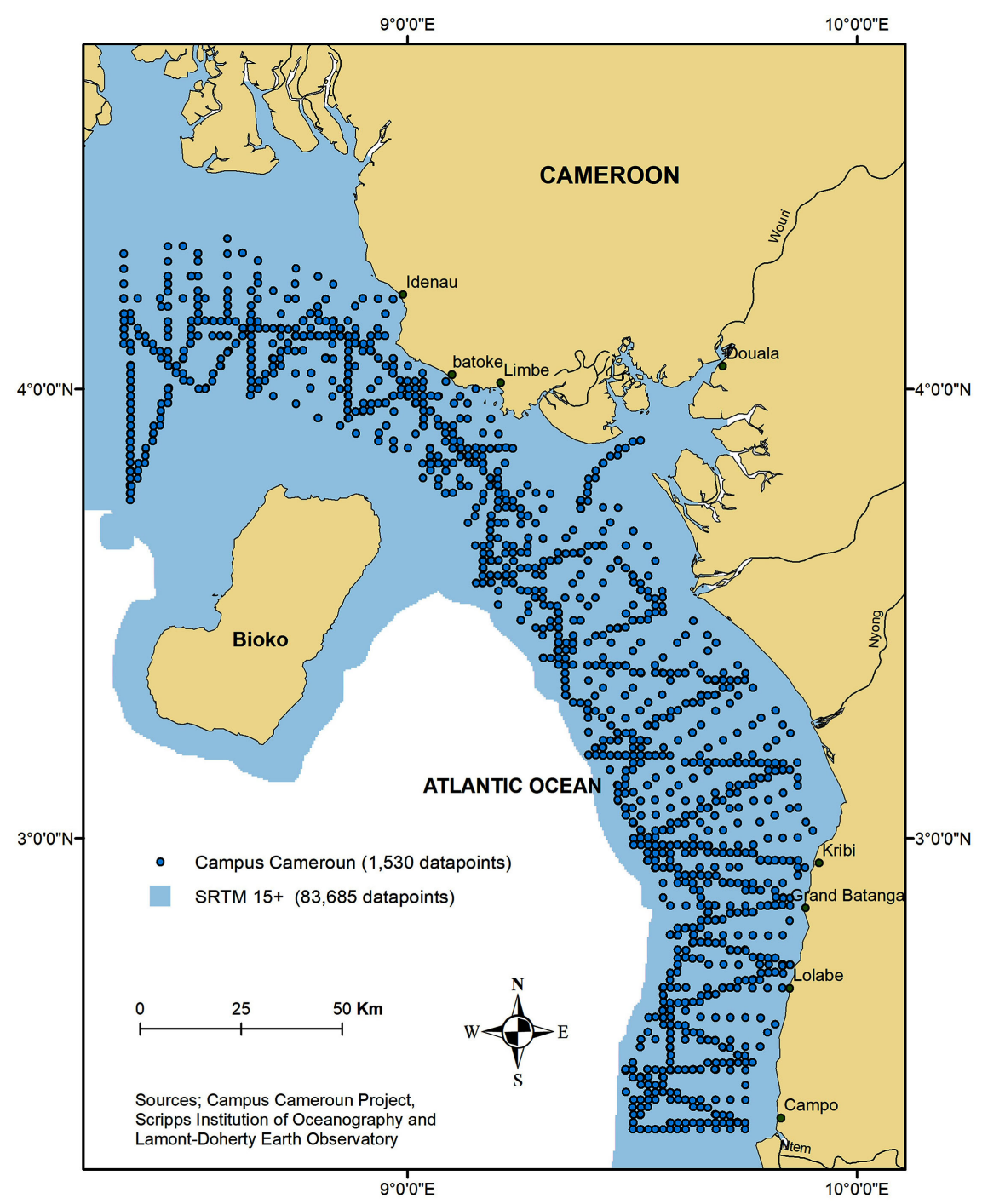

Figure 2. Data sources: XYZ data points of Campus Cameroun and SRTM15 + V2.0. 


\subsection{SRTM15 + V2.0}

The SRTM15 + V2.0 dataset used in this comparison is an extract of the $S R T M 15+V 2.0,15$ arc-second grid in ASCII XYZ-format downloaded from the website of The Scripps Institution of Oceanography on April 18, 2019 [27] and sifted by attribute querying to remove values over land and non-coastal waters deeper than $-400 \mathrm{~m}$ (Figure 2). SRTM15 $+V 2.0$ has an ocean topography data grid (DBM) made of satellites estimated seafloor topography and soundings data with a resolution of 15 arc-second (approximately 30 meters), registered to the WGS 84 common horizontal datum and a vertical datum established at sea level [28] [29] [30]. Numerous global terrain models now available are based on SRTM15 + V2.0 for the bathymetry or modeled similarly. Notable among these are Google Earth and Google Map. Since SRTM15 + V2.0 provides backend data information to numerous global terrain models, the results of its evaluation can be extended subsequently to them even though many of these models are already superseded.

Despite constant improvements [31] [32], the resolution, quality, and overall accuracy of the SRTM stack and, therefore, of SRTM $15+V 2.0$ for the coastal and shallow oceanic regions still creates some concern and explains why in areas of intense survey, models have been developed to correct imprecisions and inaccuracies Obviously, it is not yet the case for Cameroon's waters.

\section{Methodology}

Bathymetric data are made of three measurements: $x, y$ for location (position), and $\mathrm{z}$ for underwater bottom elevation [33]. Although position and elevation are independent measurements with independent accuracies, they are intrinsically linked in determining the accuracy of a bathymetric data. Errors in horizontal positional accuracy may also induce vertical errors. Therefore, any effort to compare different surveys made over the same presumed point must consider potential inaccuracies in three dimensions [34]. This is the reason why error, which encompasses both the imprecision of data and its inaccuracy, is often of great concern in marine geography.

Although they undergo an extensive quality control before their release, bathymetric datasets can still contain connate errors (which are embedded into the data and are related to the materials, the techniques used to collect those data) or, external factors errors (generated by the choice of data manipulation procedures) [35] [36] [37]. Inaccuracy is the consequences of these errors. Since it is cumbersome to verify each measured depth, accuracy assessment of underwater data can only be determined through statistical estimation, quantitative comparisons, and visual appreciation [38] [39].

Spatial data can be evaluated for the accuracy of their position, geometry, and topology. The scope of this paper is limited to the positional and completeness assessment of SRTM15 + V2.0.

Positional accuracy is the quantifiable value that represents the distance dif- 
ference (error distance) between a geospatial feature and the reality (absolute) or between two geospatial features (relative) [40]. Due to the nature of the field which makes direct verification difficult, this work is based on dataset comparison for relative positional accuracy between Campus Cameroun and SRTM15 + V2.0. The drawback of the relative approach for underwater datasets comparison is that in the absence of ground control, the assessment of datasets similarity or dissimilarity is ambiguous. It should be noted that compared to Campus Cameroun, SRTM15 + V2.0 is a more densified full-coverage terrain model. As a result, this comparison is not commutative [(Campus Cameroun, SRTM15 + V2.0) $\neq($ SRTM15 + V2.0, Campus Cameroun)] as the sampling was limited to the Campus Cameroun datapoints.

Using statistical and GIS tools [41], Campus Cameroun and SRTM15 + V2.0 were evaluated for their agreement through distance-based metrics and measures derived from datapoint coordinates sifting and surface analysis.

The first operation was to find the correlation based on exact coordinates match (intersection). For this purpose, all the data points with their attributes organized in named datasets spreadsheet were loaded into a MS SQL Server and sifted through to look for similarity. Based on their position coordinates attributes (longitude and latitude), no points of intersection was established between Campus Cameroun and the SRTM15 + V2.0. This validated the independence between surveys and indicated that Campus Cameroun data where not integrated into SRTM15 + V2.0.

The second operation made necessary by the result of the first one (no intersection points), was intended to capture the error Distance between Campus Cameroun and SRTM15 + V2.0. For that, two surface models based on Natural Neighbor Inverse Distance Weighted Interpolation (NNIDW) of depths (NNIDW Interpolation Spatial Analysis) were created (Figure 3). There is no optimal interpolation method. It is well known that each technique has different sensitivity to errors and that the quality of DBMs can be improved when making the appropriate choice of interpolator [42]. Since the choice of interpolator depends on the type of data and the spatial arrangement of the samples [43], the NNIDW interpolation method was preferred because it returns a moderate RMSE. From these DBMs three representative cross sections (Interpolate line 3-D Analysis-ArcMap, (Figure 3) and two isobaths sets (contour-surface analysis-spatial analysis-ArcMap) with contour lines at interval $-10,-20,-30,-40$, $-50,-60,-70,-80,-90,-100,-110,-120$ and -200 were generated (Figure 4 ). These profiles and derived isobaths provided the means for a quantitative and qualitative comparison.

The vertical difference between the DEM clearly visible through the profiles was assess after extracting the cell values of the SRTM15 + V2.0 raster corresponding to the point features of Campus Cameroun. (Extract Values to Points Spatial Analyst-ArcMap). For consistency and to avoid bugs created by outliers, the sample was limited to a maximum depth difference threshold equal or supe- 
rior to $-120 \mathrm{~m}$ (approximate break depth) and a CTE (Common Table Expression) was used to remove duplicates. The final sample turns out to 1523 records. The height accuracy was then estimated on basis of the depth difference between SRTM15 + V2.0 data points and the Campus Cameroun corresponding values. These relative vertical measured errors were aggregated to find the RMSE, the Mean, Median and other parameters that quantify the vertical difference between Campus Cameroun and SRTM15 + V2.0.

Although they are interpolations of underlying data plagued by a process called terracing with accuracy subject to interpretation due to their inherent uncertainty, isobaths were used to evaluate the horizontal displacement [44] (Figure 4). The error measurements were obtained by generating control points on Campus Cameroun isobaths (Data Management-Sampling ArcMap) and using them to establish the geodesic distance (point to line) to the nearest or closest SRTM15 + V2.0 comparing isobath using the Near (Proximity-Analysis tool

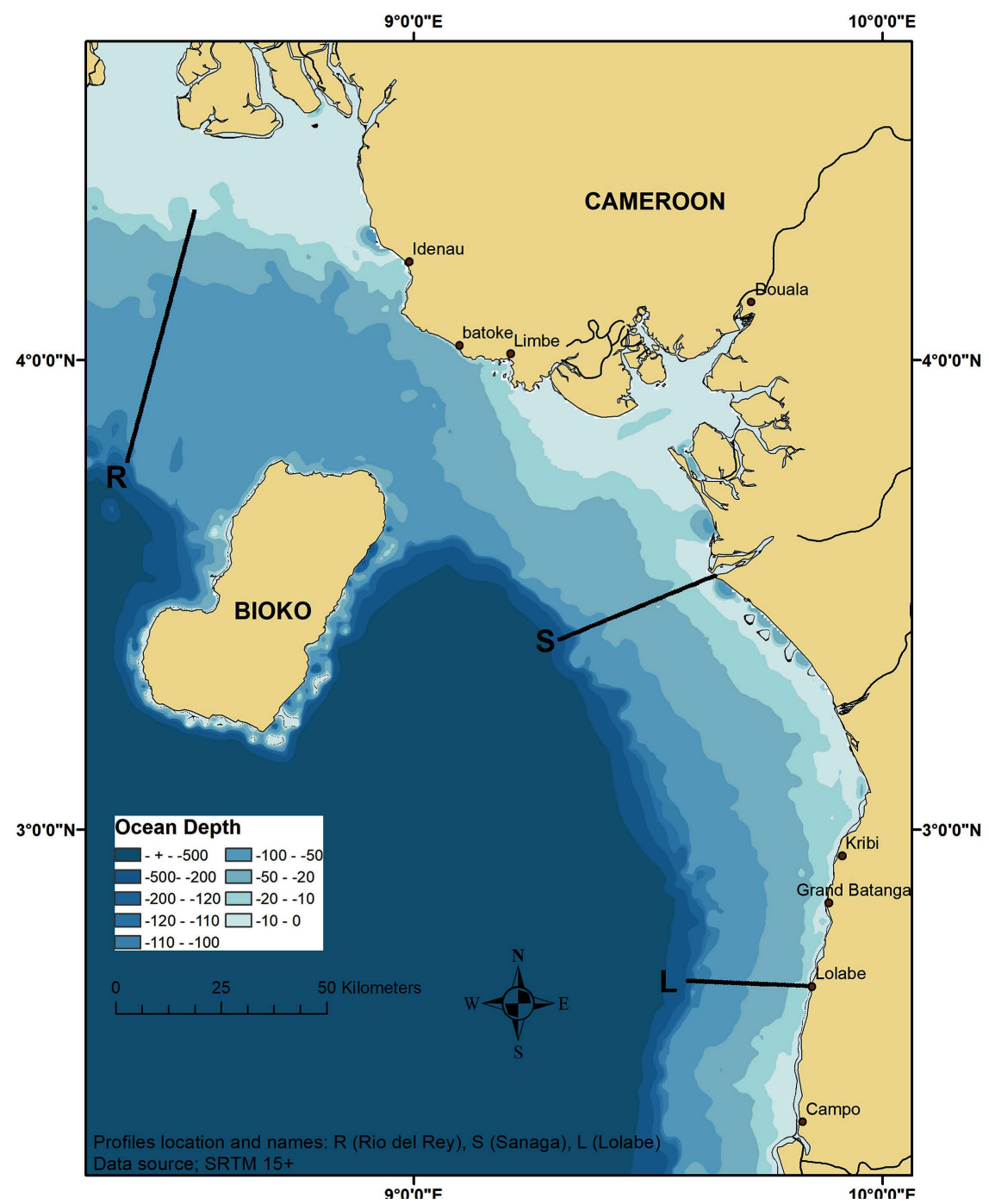

Figure 3. Cameroun continental seafloor depths from SRTM15 + V2.0 and cross-sections location. 


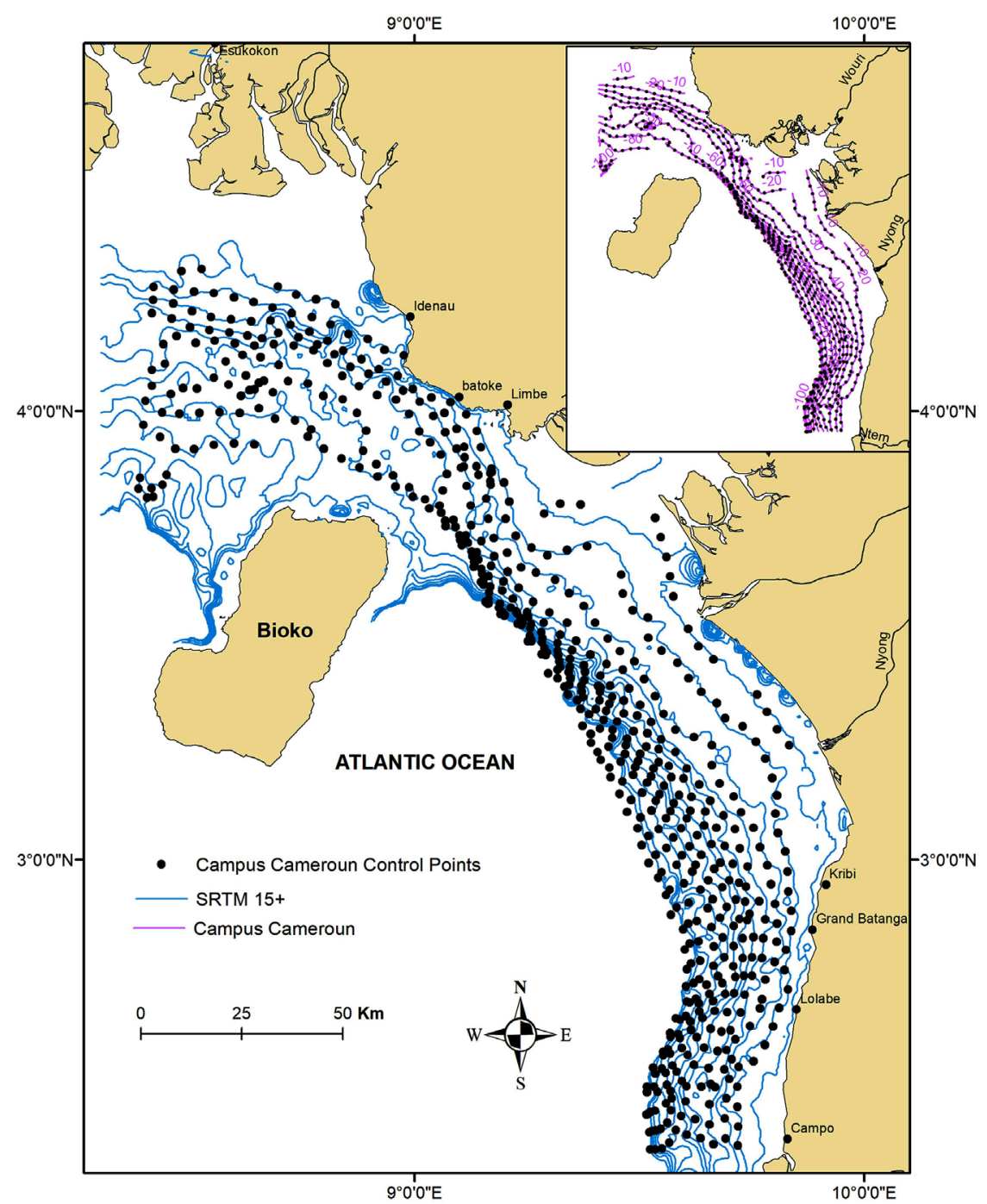

Figure 4. Generated control points from Campus Cameroun isobaths (Subset) with SRTM15 + V2.0 for distance estimates.

ArcMap). On the grounds of the Waldo Tobler law [45] on spatial dependence and spatial autocorrelation which stated that "everything is related to everything else, but near things are more related than distant things", of the 593 points obtained, and to prevent analysis errors, 586 were chosen for being at a distance inferior or equal to $2000 \mathrm{~m}$ from the nearest SRTM15 + V2.0 isobath (Figure 4). As with the ArcGIS Data Reviewer Positional Accuracy Assessment Tool (PAAT), the relative horizontal error distances obtained were used to determine variables such as the Mean, the Median and their derived parameters (such as the RMSE, the three-sigma threshold and the confidence interval), which all help to quantitatively assess the horizontal variance between Campus Cameroun and SRTM15 + V2.0.

The level of shape matching between Campus Cameroun and SRTM15 + V2.0 isobaths was statistically quantified (sinuosity index) by running a relate python script via ArcGIS Field Calculator [46]. 
Finally, the superimposition of isobaths on Google Earth allows a Visual analysis [47].

\section{Results and Analyses}

\subsection{Vertical Accuracy}

If the below cross sections of the Cameroon continental shelf from interpolated Campus Cameroun and SRTM15 + V2.0 DBM show an overall similar appearance, in detail vertical disparities are noticeable. At a glance, one can notice that (except in some few points) Campus Cameroun is deeper than SRTM15 + V2.0. In the Rio del rey and Sanaga sections the depth difference is bigger than in the Lolabe section. Also, the depth difference in general is higher on the outer area of the shelf (Figure 5). A thorough scrutiny of depth difference reveals that of the 1523 sample points, 1129 (74.13\%) of Campus Cameroun are deeper than on SRTM15 + V2.0.

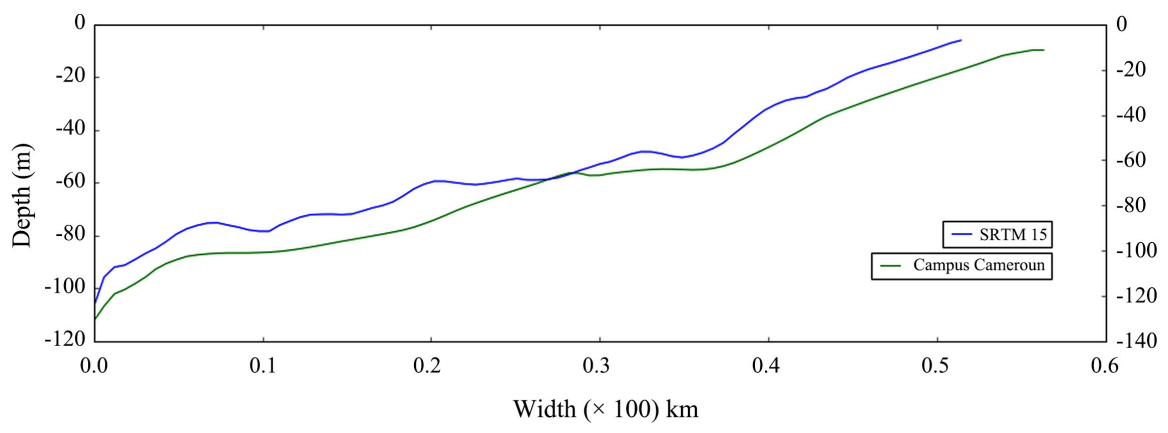

Rio del rey (R) Profiles

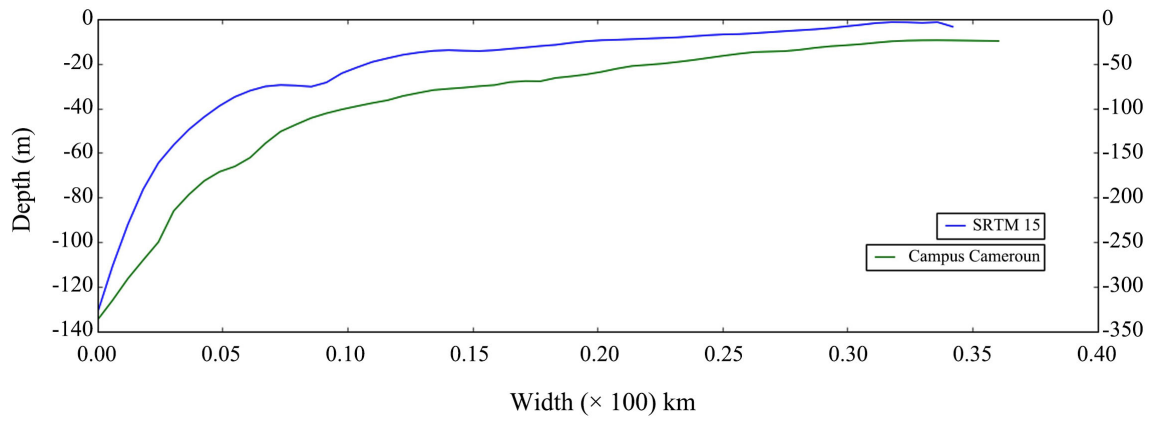

Sanaga (S) Profiles

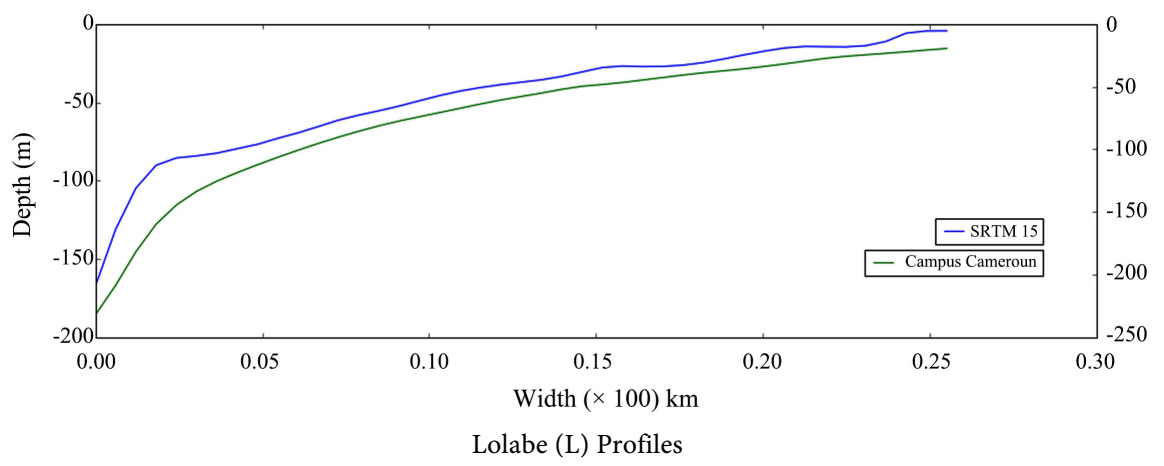

Figure 5. Cross sections of Campus Cameroun and SRTM15 + V2.0. 
The variable values of depth difference between Campus Cameroun and the SRTM15 + V2.0 obtained from the extraction of the points coordinates (Table 1) provide a summary description of the correlation between these datasets. It is well known, as demonstrated in Table 1 that outliers (three sigma) degrade data accuracy. To reduce their influence on statistical analysis, they were removed from the raw data.

Complementing the above values, the underlying density distribution of depths (Figure 6) provides a comprehensive graphical view of the goodness-of-fit between these datasets. The Skew index at 2.92 denotes a highly skewed distribution with a heavy-tails that is translated in a Kurtosis index of 12.60 . This Leptokurtic distribution is the consequence of the high variance between data in the outer area of the continental shelf.

The correlation coefficient of 0.95 between Campus Cameroun depths and SRTM15 + V2.0 depths denotes a strong positive linear relationship (Figure 7) which is reflected in the similarity of profiles shape. As depth increases, so do the depth difference (Table 2).

The median relative vertical distance between Campus Cameroun and SRTM15 + V2.0 is established at $2.46 \mathrm{~m}$. For Yap et al., the median vertical error distance near water bodies is $2.86 \mathrm{~m}$.

\subsection{Horizontal Accuracy}

Despite the similarity of the profiles, the non-positional alignment of the forms such as the ledge near the break on the Sanaga profile or the inflexion circa -60 $m$ in Rio del rey section, hint of a slip or a horizontal displacement.

The measures of the relative positional distance between Campus Cameroun and SRTM15 + V2.0 from the isobaths (Table 3) also bear some important indications (Figure 8).

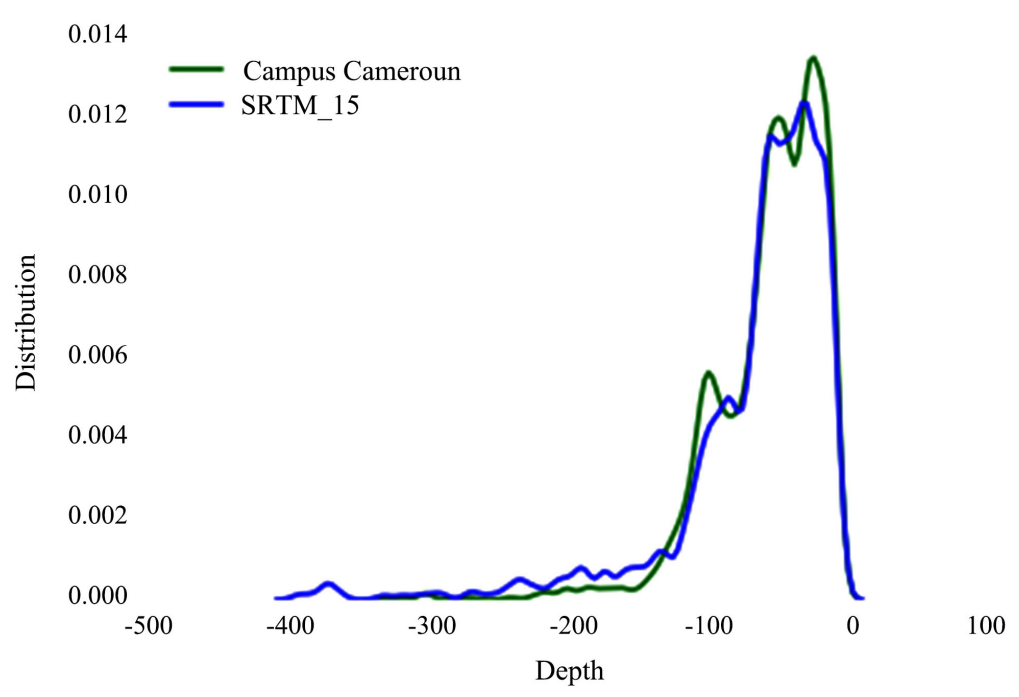

Figure 6. Depth distribution between Campus Cameroun and SRTM15 + V2.0. The long tail indicates the presence of outliers. 




Figure 7. Linear regression showing a strong relationship between a SRTM15 + V2.0 and Campus Cameroun depths.



Figure 8. Distribution of distance between Campus Cameroun and SRTM15 + V2.0.

Table 1. Variables of depth difference between Campus Cameroun and SRTM15 + V2.0.

\begin{tabular}{ccc}
\hline Variable & Raw Value & Value after Outliers removed \\
\hline Sample count & 1523 & 1490 \\
Min Depth Difference $(\mathrm{m})$ & 0 & 0 \\
Max Depth Difference $(\mathrm{m})$ & 257.53 & 94.15 \\
Mode Depth Difference & 1.0 & 1.0 \\
Mean Depth Difference (m) & 9.53 & 6.11 \\
Median Depth Difference (m) & 2.57 & 2.46 \\
95\% DD confidence interval & $8.10,10.96$ & $5.34,6.89$ \\
RMSE & 30.01 & 16.48 \\
Standard Deviation & 28.46 & 15.31 \\
Three sigma & $-75.85,94.93$ & $\mathrm{NA}$ \\
Correlation coefficient & 0.90 & 0.95 \\
kurtosis & 29.72 & 12.60 \\
skewness & 4.90 & 2.92 \\
\hline
\end{tabular}


Table 2. Depth difference values between Campus Cameroun and SRTM15 + V2.0 by depths.

\begin{tabular}{cccc}
\hline By depth & Min depth difference $(\mathrm{m})$ & Max depth difference $(\mathrm{m})$ & Mean depth difference $(\mathrm{m})$ \\
\hline $0-10$ & 0 & 7.15 & 2.13 \\
$11-20$ & 0 & 10.83 & 1.93 \\
$21-30$ & 0 & 54.97 & 2.85 \\
$31-40$ & 0 & 17.88 & 3.79 \\
$41-50$ & 0 & 51.42 & 4.01 \\
$51-60$ & 0.02 & 26.13 & 3.81 \\
$61-70$ & 0 & 46.40 & 6.63 \\
$71-80$ & 0 & 28.73 & 7.08 \\
$81-90$ & 0.12 & 27.28 & 7.49 \\
$91-100$ & 0.24 & 21.23 & 6.22 \\
$101-110$ & 0.09 & 37.02 & 8.34 \\
$111-120$ & 0.15 & 38.90 & 9.91 \\
\hline
\end{tabular}

Table 3. Linear distance statistical values between Campus Cameroun and SRTM15 + V2.0.

\begin{tabular}{ccc}
\hline Variable & Raw Value & Value after outliers removed \\
\hline Sample count & 593 & 586 \\
Minimum Distance (m) & 5.10 & 5.10 \\
Maximum Distance (m) & 4508.01 & 2565.50 \\
Mean Distance (m) & 694.54 & 663.21 \\
Median Distance (m) & 504.09 & 499.27 \\
Mode Distance (m) & 5.10 & 5.10 \\
RMSE & 939.01 & 869.50 \\
Standard Deviation & 632.48 & 562.78 \\
Correlation coefficient & 0.18 & 0.15 \\
kurtosis & 4.18 & 0.90 \\
skewness & 1.70 & 1.18 \\
Three sigma & $-1202.89,2591.99$ & NA \\
$95 \%$ confidence-interval & $643.53,745.55$ & $617.55,708.87$ \\
\hline
\end{tabular}

With a skew index of 1.18 and a kurtosis index of 0.90 , the linear distance distribution between SRTM15 + V2.0 and Campus Cameroun is platykurtic because of its thin tails that denote a constancy in the displacement regardless of the depths and fewer extreme values as shown in the correlation Figure 9. The 0.15 Pearson's coefficient for the correlation between the linear distance and the depths between Campus Cameroun and the SRTM15 + V2.0 indicates a non-linear to very weak linear relationship (Figure 9). 


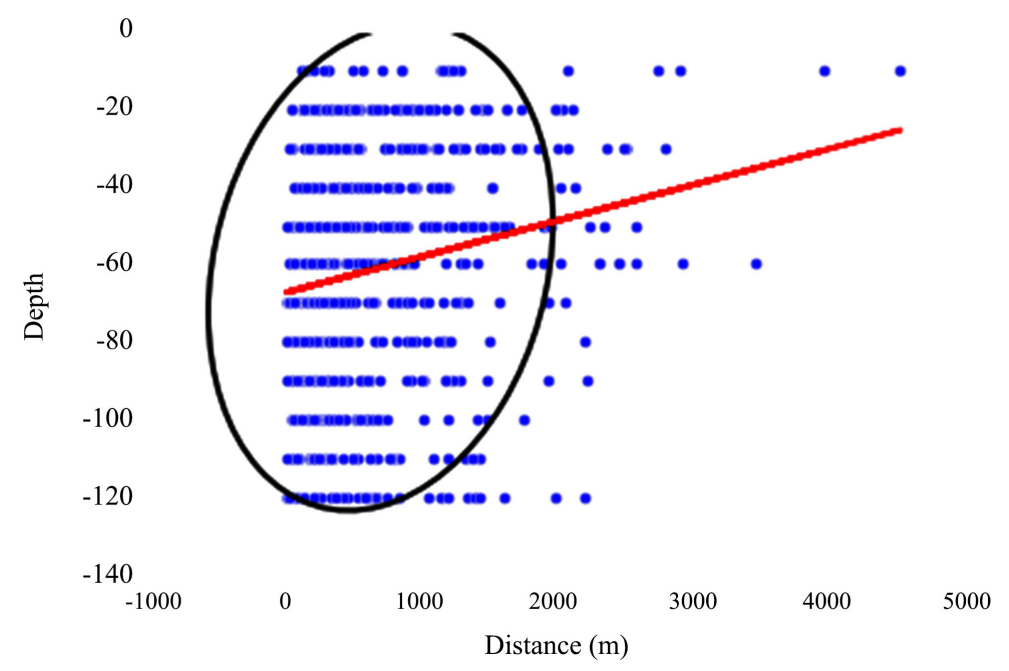

Figure 9. Distance and depth Linear regression.

As one can notice in the Table 3 and Table 4, the relative positional accuracy between Campus Cameroun and SRTM15 + V2.0 is not depth dependent. There is no correlation between linear distance, depth difference and depth even though the mean depth difference increases as depth increases (Figure 10).

Geographically, there is no established trend or pattern for the distribution of the linear distance between Campus Cameroun and SRTM15 + V2.0.

The conclusion is that the horizontal relative displacement distance between Campus Cameroun and SRTM15 + V2.0 is linearly 499.27 m (median). A similar shift (500 m approximatively) in ETOPO 2 and GEBCO 14 was attributed to a mislocation or misregistration of the grids [48].

\subsection{Visual Analysis}

Visual appreciation and comparison of the isobaths that the Figure 11 renders possible shows that SRTM15 + V2.0 is generally reproducing the same sinuosity and respect the same overall orientation of Campus Cameroun even though it contains some artifacts. The two datasets are topologically consistent even if they do not fit each other in terms of position. General morphologic characteristics are similar for both datasets. However, there are some significant elements to acknowledge. When scrutinizing the overlaid map, it clearly appears that SRTM15 + V2.0 is in latitude and longitude shifted northward and eastward of the Campus Cameroun. The perceptible signs of this northward displacement can be observed in the Rio del rey area. The landward shift (eastward) is clearly noticeable in the meridional portion of the Cameroon continental shelf where SRTM15 + V2.0 isobaths are East of their corresponding reference's isobaths.

When it comes to isobaths shape matching, although depth contour of SRTM15 + V2.0 shows patterns like those of Campus Cameroun, the isobaths derived from SRTM15 + V2.0 with a mean sinuosity index of 0.43 , a standard deviation of 0.17 and a RSME of 0.66 are more sinuous and smoother than those extracted from Campus Cameroun whose mean sinuosity index is 0.59 , standard 
deviation 0.65 and RSME 0.77 . This is the translation of SRTM15 + V2.0 being more detailed data wise (tighter mesh) than Campus Cameroun.

With the increasing interest in coastal monitoring and research, and because it is highly demanding and costly, nearshore bathymetry is also often scrutinized when judging the accuracy of Bathymetric model based on remote sensing techniques. Although the Global Self-consistent, Hierarchical, High-resolution Shoreline (GSHHS) [48] was used to assess the integration of topography and bathymetry, SRTM15 + V2.0, because of the positional displacement mentioned beyond, contains a numerous artifacts in the near shore with depth less than -10 $\mathrm{m}$. For that reason, the transition with the continent is questionable, especially between the mouth of the Sanaga river and Kribi. It should be noted that there is a need for valuable information on this part of the studied area because it was not surveyed during Campus Cameroun due to the presence of numerous shoals and the height of the boat draft.

Table 4. Measures and metrics from Near Neighbour (QGIS) spatial joins between Campus Cameroun and SRTM15 + V2.0 by depth.

\begin{tabular}{ccc}
\hline Depth & Mean Distance $(\mathrm{m})$ & Mean depth difference $(\mathrm{m})$ \\
\hline $0-10$ & 954.63 & 2.19 \\
$11-20$ & 994.57 & 1.93 \\
$21-30$ & 980.14 & 2.85 \\
$31-40$ & 981.51 & 3.79 \\
$41-50$ & 940.42 & 4.01 \\
$51-60$ & 950.87 & 3.81 \\
$61-70$ & 975.22 & 6.63 \\
$71-80$ & 987.87 & 7.08 \\
$81-90$ & 1011.40 & 7.49 \\
$91-100$ & 1005.57 & 6.22 \\
$101-110$ & 1014.42 & 8.34 \\
$111-120$ & 1007.58 & 9.91 \\
\hline
\end{tabular}

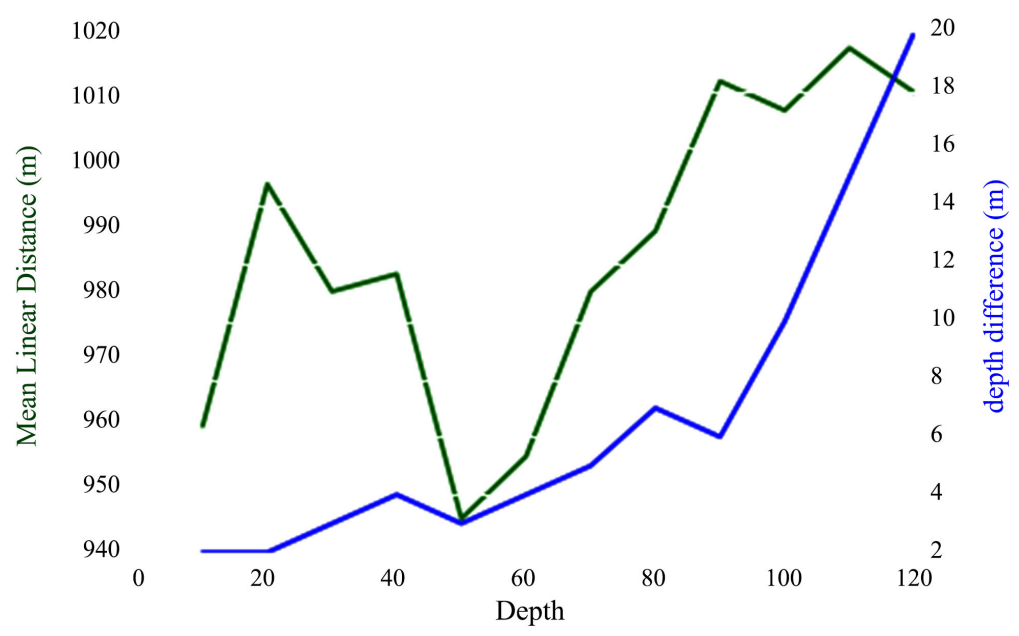

Figure 10. Correlation between mean linear distance, mean depth difference and depth between Campus Cameroun and SRTM15 + V2.0. 


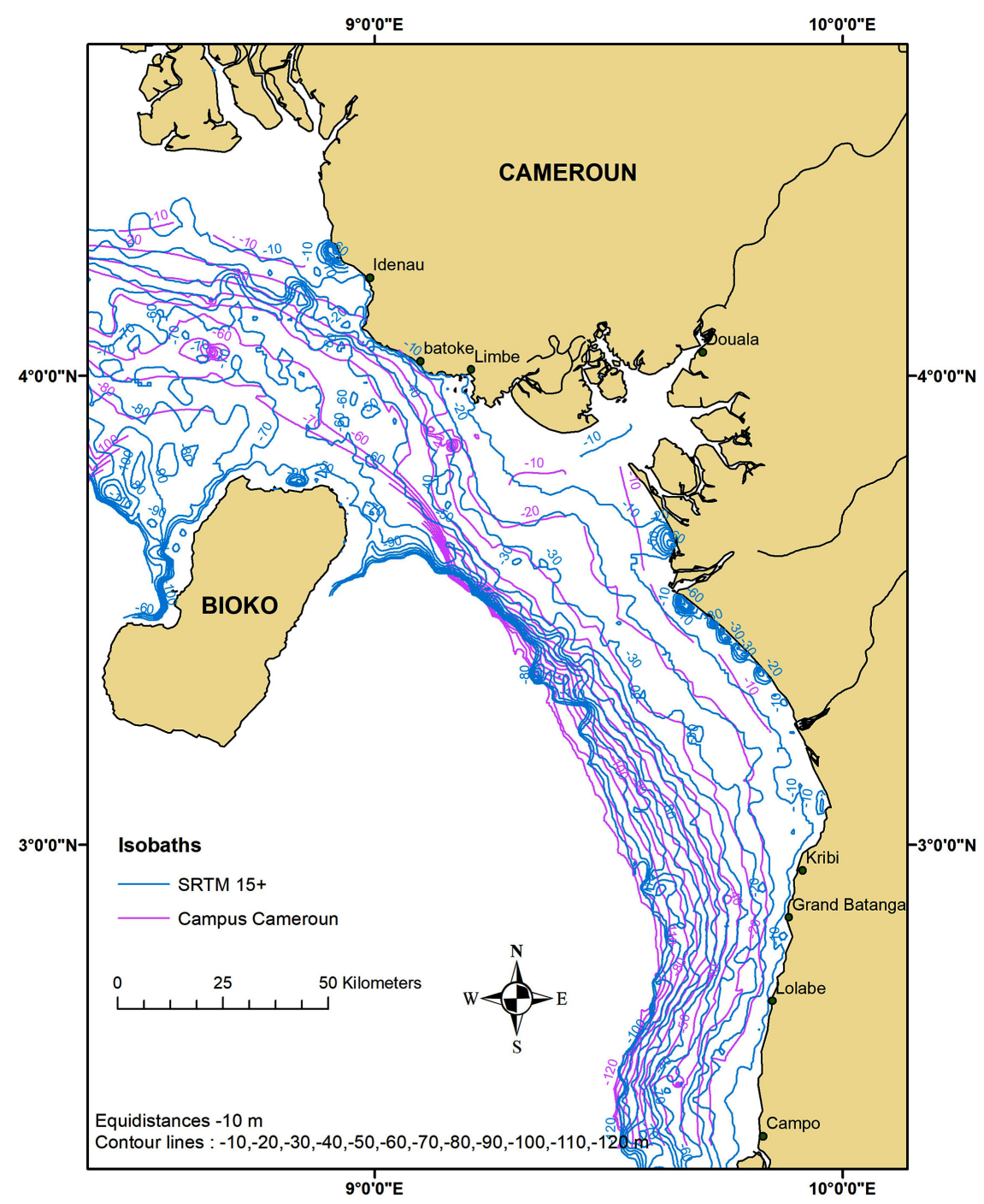

Figure 11. Superimposition of Campus Cameroun and SRTM15 + V2.0 isobaths.

Overlaying to Google imagery [49], Campus Cameroun (Figure 12) and SRTM15 + V2.0 (Figure 13) shows their level of completeness. The close match of their features confirms that SRTM15 + V2.0 dataset is suitable for academic research purposes.

\section{Discussion and Limitation}

The different measures and metrics demonstrate that there is a horizontal displacement between Campus Cameroun and SRTM15 + V2.0 even though they show a higher accuracy level of conformity.

As noted, throughout this paper, SRTM15 + V2.0, relative horizontal positional inaccuracy is the result of a northward and eastward shift from Campus Cameroun. However, this positional inaccuracy did not alter the geomorphic consistency of this dataset since it achieves a higher degree of geometry fidelity as proven by the shape similarity of its isobaths with the reference. 


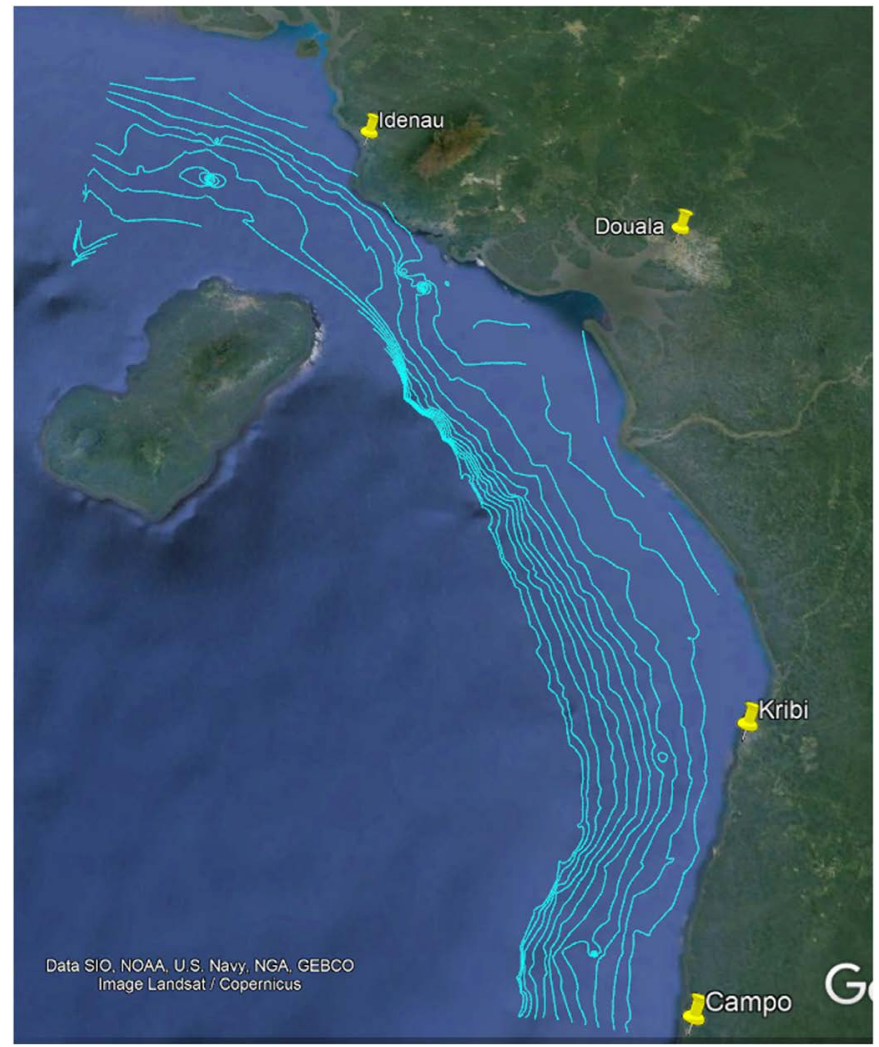

Figure 12. Campus Cameroun isobaths set Overlaying Google Earth.

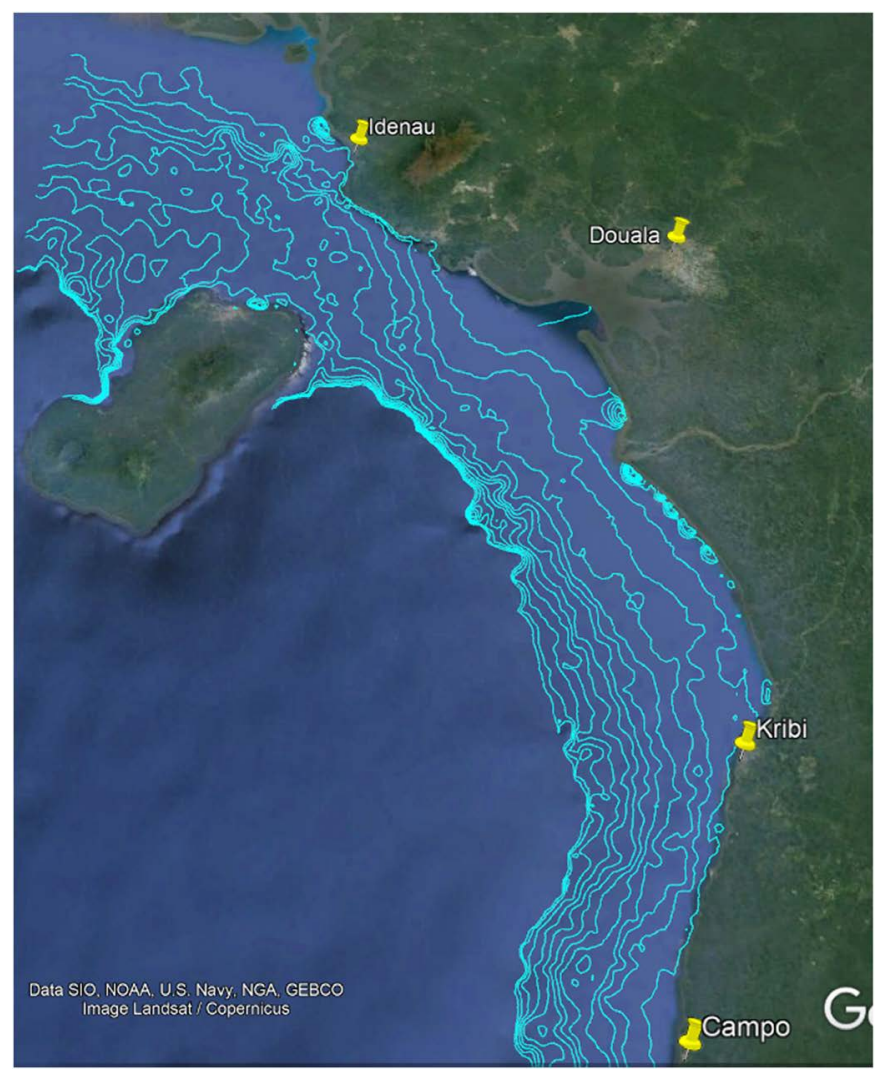

Figure 13. SRTM15 + V2.0 isobaths set Overlaying Google Earth. 
Highly accurate datasets are the key for reliable results. The need for accuracy must be determined by the level of truthfulness expected. Excessive accuracy is costly and produces considerable unnecessary details [50]. Therefore, despite this horizontal accuracy issue, SRTM15 + V2.0 constitutes an important source of free and publicly available geographic information that can be confidently used in a broad geomorphological study of the continental shelf of Cameroon since currently there is not perfect dataset of the Cameroon's seafloor.

\section{Conclusions}

Through a comparative accuracy assessment, using a suite of measures, this study established that, as far as positional accuracy is concerned, there is an overall latitudinal northward and longitudinal eastward shift of SRTM15 + V2.0 to the Campus Cameroun which is the reference. The systemic consistency of this tilt-which is the main source of the positional inaccuracy-can be attributed to a misregistration. When it comes to their conformity to the underwater features, Campus Cameroun and SRTM15 + V2.0 both achieve a very high level of accuracy as their isobaths shape and sinuosity are similar in most of the area. Therefore, as a conclusion of this accuracy evaluation, SRTM15 + V2.0 is a complete and reliable alternate data source for geomorphological research on the Cameroon continental shelf.

Marine geomorphology is a poor relative of the Cameroon geomorphology. This paper provides a scientific rationale and limitations for using SRTM15 + V2.0 in its current stage of development for geomorphology research on the maritime Cameroon in the absence of newer option and while awaiting a possible multibeam survey. It must be borne in mind that detailed and accurate knowledge of the seabed is paramount to the development of the maritime territory [51].

\section{Acknowledgements}

This research received no specific grant from any funding agency in the public, commercial, or not-for-profit sectors. I would like to sincerely thank Dr. Thomas Pingel (Virginia Polytechnic Institute and State University), Pr Alexie Tcheuyap (University of Toronto), Pr. Etienne Lassi (University of Manitoba) and Engr. Nels Degn (Exelon) whose thoughtful recommendations and feedback greatly strengthened the manuscript.

\section{Conflicts of Interest}

The authors declare no conflicts of interest regarding the publication of this paper.

\section{References}

[1] Smith, W.H.F. and Sandwell, D.T. (1997) Global Seafloor Topography from Satellite Altimetry and Ship Depth Soundings, Science, 277, 1957-1962. 
https://doi.org/10.1126/science.277.5334.1956

[2] Laughton, A. and Shipman, S. (2000) Historical Methods of Depth Measurement. In: Continental Shelf Limits: The Scientific and Legal Interface, Oxford University Press, Oxford, 124-138.

[3] Clarke, J.H. (2000) Present-Day Methods of Depth Measurement. In: Cook and Carleton, Eds., Continental Shelf Limits. The Scientific and Legal Interface, Oxford University Press, Oxford, 139-158.

[4] Byrnes, M.R., Baker, J.L. and Li, F. (2002) Quantifying Potential Measurement Errors and Uncertainties Associated with Bathymetric Change Analysis. ERDC/CHL CHETN-IV-50 September.

[5] Harris, P., Macmillan-Lawler, M., Rupp, J. and Baker, E. (2014) Geomorphology of the Oceans. Marine Geology, 352, 4-24. https://doi.org/10.1016/j.margeo.2014.01.011

[6] Jakobsson, M., Mayer, L. and Monahan, D. (2015) Arctic Ocean Bathymetry: A Necessary Geospatial Framework. Arctic, 68, 41-47.

https://doi.org/10.14430/arctic4451

[7] Monahan, D. (2015) Altimetry and the Law of the Sea Definition of the Continental Shelf. Global Bathymetry for Oceanography, Geophysics and Climatology. Altimetry and UNCLOS.

[8] Lecours, V., Dolan, M., Micallef, A. and Lucieer, V. (2016) A Review of Marine Geomorphometry, the Quantitative Study of the Seafloor. Hydrology and Earth System Sciences, 20, 3207-3244. https://doi.org/10.5194/hess-20-3207-2016

[9] Crosnier, A. (1964) Fonds de pêche le long des côtes de la République Fédérale du Cameroun, cahiers 0.r.s.t.o.m. océanographie $\mathrm{n}^{\circ}$ spécial.

[10] Giresse, P., Megope Foonde, J., Ngueutchoua, G., Aloisi, J., Kuété, M. and Monteillet, J. (1996) Carte sédimentologique du plateau continental du Cameroun et notice explicative 111, Orstom, Paris.

[11] Katsuto, U. (2014) Compilation and Validation of Bathymetric Data for the South China Sea with an Emphasis on Shallow Region. Engineering Sciences Reports, Kyushu University, 35, 7-13.

[12] Marks, K.M. and Smith, W.H.F. (2006) An Evaluation of Publicly Available Global Bathymetry Grids. Marine Geophysical Researches, 27, 19-34. https://doi.org/10.1007/s11001-005-2095-4

[13] Ryan, W.B.F., Carbotte, S.M., Coplan, J.O., O’Hara, S., Melkonian, A., Arko, R., Weissel, R.A., Ferrini, V., Goodwillie, A., Nitsche, F.J., Bonczkowski, J. and Zemsky, R. (2009) Global Multi-Resolution Topography Synthesis. Geochemistry, Geophysics, Geosystems, 10, Q03014. https://doi.org/10.1029/2008GC002332

[14] Congalton, R. (2001) Accuracy Assessment and Validation of Remotely Sensed and Other Spatial Information. International Journal of Wildland Fire, 10, 321-328. https://doi.org/10.1071/WF01031

[15] Jakobsson, M., Calder, B. and Mayer, L. (2002) On the Effect of Random Errors in Gridded Bathymetric Compilations. Journal of Geophysical Research, 107, ETG 14-1-ETG 14-11. https://doi.org/10.1029/2001JB000616

[16] Jakobsson, M., Armstrong, A., Calder, B., Huff, L., Mayer, L. and Ward, L. (2005) On the Use of Historical Bathymetric Data to Determine Changes in Bathymetry an Analysis of Errors and Application to Great Bay Estuary, NH. International Hydrographic Review, 6, 1-17.

[17] Pe'eri, S., et al. (2014) Satellite Remote Sensing as a Reconnaissance Tool for As- 
sessing Nautical Chart Adequacy and Completeness. Marine Geodesy, 37, 293-314. https://doi.org/10.1080/01490419.2014.902880

[18] Harris, P. and Macmillan-Lawler, M. (2016) Global Overview of Continental Shelf Geomorphology Based on the SRTM30_PLUS 30-Arc Second Database. In: Finkle, C.W. and Makowski, C., Eds., Emerging Mapping Techniques for Autonomous Underwater Vehicles (AUVs), Springer, Berlin, 169-190.

https://doi.org/10.1007/978-3-319-25121-9 7

[19] Olson, C.J., Becker, J.J. and Sandwell, D.T. (2016) SRTM15 PLUS: Data Fusion of Shuttle Radar Topography Mission (SRTM) Land Topography with Measured and Estimated Seafloor Topography (NCEI Accession 0150537).

[20] Ariza Lopez, F.J. and Atkinson Gordo, A.D. (2008) Analysis of Some Positional Accuracy Assessment Methodologies. Journal of Surveying Engineering, 134, 45-54.

[21] Nikolakopoulos, K.G., Kamaratakis, E.K. and Chrysoulakis, N. (2006) SRTM vs. ASTER Elevation Products. Comparison for Two Regions in Crete, Greece. International Journal of Remote Sensing, 27, 4819-4838. https://doi.org/10.1080/01431160600835853

[22] Hirt, C., Filmer, M.S. and Featherstone, W.E. (2010) Comparison and Validation of Recent Freely-Available ASTER-GDEM ver1, SRTM ver4.1 and GEODATA DEM-9S ver3 Digital Elevation Models over Australia. Australian Journal of Earth Sciences, 57, 337-347. https://doi.org/10.1080/08120091003677553

[23] Abramova, A. (2012) Comparison and Evaluation of Global Publicly Available Bathymetry Grids in the Arctic. University of New Hampshire, Durham, 150 p.

[24] Pulighe, G., Baiocchi, V. and Lupia, F. (2015) Horizontal Accuracy Assessment of Very High-Resolution Google Earth Images in the City of Rome, Italy. International Journal of Digital Earth, 9, 342-362. https://doi.org/10.1080/17538947.2015.1031716

[25] Yap, L., Houetchak Kandé, L., Nouayou, R., Kamguia, J., Nasser Abdou Ngouh, N.A. and Makuate, M.B. (2018) Vertical Accuracy Evaluation of Freely Available Latest High-Resolution $(30 \mathrm{~m}$ ) Global Digital Elevation Models over Cameroon (Central Africa) with GPS/Leveling Ground Control Points. International Journal of Digital Earth, 12, 500-524. https://doi.org/10.1080/17538947.2018.1458163

[26] Wells, D., Beck, N., Delikaraoglou, D., Kleusberg, A., Krakiwsky, E.J., Lachapelle, G., Langley, R.B., Nakiboglu, M., Schwarz, K.P., Tranquilla, J.M. and Vanicek, P. (1999) Guide to GPS Positioning. Canadian GPS Associates and University of New Brunswick, Fredericton.

[27] Scripps Institute of Oceanography (2019) Satellite Geodesy: Extract Topography from Global 15 Arc Second Grid in ASCII XYZ-Format SRTM15 + V2.0. https://topex.ucsd.edu/cgi-bin/get srtm15.cgi

[28] NOAA (2007) Topographic and Bathymetric Data Considerations: Datums, Datum Conversion Techniques, and Data Integration, Part II of a Roadmap to a Seamless Topobathy Surface. Technical Report, NOAA/CSC/20718-PUB.

[29] Becker, J.J. and Sandwell, D.T. (2012) Development of Global Bathymetry and Topography at 15 Arc Seconds. American Geophysical Union, Fall Meeting.

[30] Tozer, B., Sandwell, D.T., Smith, W.H.F., Olson, C., Beale, J.R. and Wessel, P. (2019) Global Bathymetry and Topography at 15 Arc Seconds: SRTM15. Earth and Space Science. https://doi.org/10.1029/2019EA000658

[31] Smith, W.H.F. (1993) On the Accuracy of Digital Bathymetry Data. Journal of Geophysical Research, 98, 9591-9603. https://doi.org/10.1029/93JB00716

[32] Amante, C. and Eakins, B.W. (2009) ETOPO1 1 Arc-Minute Global Relief Model: 
Procedures, Data Sources and Analysis. NOAA Technical Memorandum NESDIS, NGDC-24, 19 p.

[33] Goodchild, M.F. and Gopal, S. (1989) The Accuracy of Spatial Databases. Taylor and Francis, London, 290 p.

[34] Becker, J.J., Sandwell, D.T., Smith, W.H.F., Braud, J., Binder, B., Depner, J., Fabre, D., Factor, J., Ingalls, S., Kim, S.-H., Ladner, R., Marks, K., Nelson, S., Pharaoh, A., Sharman, G., Trimmer, R., Rosenburg, J.V., Wallace, G. and Weatherall, P. (2009) Global Bathymetry and Elevation Data at 30 Arc Seconds Resolution: SRTM15 + V2.0. Marine Geodesy, 32, 355-371. https://doi.org/10.1080/01490410903297766

[35] Zhang, J. and Goodchild, M.F. (2002) Uncertainty in Geographical Information. CRC Press, Boca Raton. https://doi.org/10.4324/9780203471326

[36] Jakobsson, M., Calder, B. and Mayer, L. (2002) On the Effect of Random Errors in Gridded Bathymetric Compilations. Journal of Geophysical Research, 107, 2358. https://doi.org/10.1029/2001JB000616

[37] Weatherall, P., Marks, K.M., Jakobsson, M., Schmitt, T., Tani, S., Arndt, J.E., Rovere, M., Chayes, D., Vicki Ferrini, V. and Wigley, R. (2015) A New Digital Bathymetric Model of the World's Oceans. Earth and Space Science, 2, 331-345. https://doi.org/10.1002/2015EA000107

[38] Thapa, K. (1992) Accuracy of Spatial Data Used in Information Geographic Systems. Photogrammetric Engineering and Remote Sensing, 58, 835-841.

[39] Robinson, T.P. and Metternicht, G. (2006) Testing the Performance of Spatial Interpolation Techniques for Mapping Soil Properties. Computers and Electronics in Agriculture, 50, 97-108. https://doi.org/10.1016/j.compag.2005.07.003

[40] Burroughs, P.A. (1986) Principles of Geographical Information Systems for Land Resources Assessment. Clarendon Press, Oxford.

[41] Longley, P., Goodchild, M., Maguire, D. and Rhind, D. (2015) Geographic Information Science and Systems. 4th Edition, Wiley, Hoboken.

[42] Li, J. and Heap, A.D. (2011) A Review of Comparative Studies of Spatial Interpolation Methods in Environmental Sciences: Performance and Impact Factors. Ecological Informatics, 6, 228-241. https://doi.org/10.1016/j.ecoinf.2010.12.003

[43] Šiljeg, A., Lozic, S. and Šiljeg, S. (2015) A Comparison of Interpolation Methods on the Basis of Data Obtained from a Bathymetric Survey of Lake Vrana, Croatia. Hydrology and Earth System Sciences, 19, 3653-3666. https://doi.org/10.5194/hess-19-3653-2015

[44] Jakobsson, M., Calder, B., Mayer, L. and Armstrong, A. (2006) The Uncertainty of a Bathymetric Contour: Implications for the Cut-Off Line. Accuracies and Uncertainties in Maritime Boundaries and Outer Limits, ABLOS Conference [CD-ROM], Int. Hydrol. Bur., Monaco, 2001.

http://citeseerx.ist.psu.edu/viewdoc/download?doi=10.1.1.365.1000\&rep=rep1\&type $=\mathrm{pdf}$

[45] Tobler, W.R. (1970) A Computer Movie Simulating Urban Growth in the Detroit Region. Economic Geography, 46, 234-240. https://doi.org/10.2307/143141

[46] Anderson, D., Ames, D. and Yang, P. (2014) Quantitative Methods for Comparing Different Polyline Stream Network Models. Journal of Geographic Information System, 6, 88-98. https://doi.org/10.4236/jgis.2014.62010

[47] Marks, K.M., Smith, W.H.F. and Sandwell, D.T. (2010) Evolution of Errors in the Altimetry Bathymetry Model Used by Google Earth and GEBCO. Marine Geophysical Research, 31, 223-238. https://doi.org/10.1007/s11001-010-9102-0 
[48] Wessel, P. and Smith, W.H.F. (1996) A Global, Self-Consistent, Hierarchical, High-Resolution Shoreline Database. Journal of Geophysical Research, 101, 8741-8743. https://doi.org/10.1029/96]B00104

[49] Google Earth Pro, V 7.3.2.5776, Image Landsat/Copernicus, Data: SIO, NOAA, U.S. Navy, NGA, GEBCO, Image IBCAO, March 5, 2019.

https://www.google.com/earth/

[50] Wölfl, A.-C., Snaith, H., Amirebrahimi, S., Devey, C.W., Dorschel, B., Ferrini, V., Huvenne, V.A.I., Jakobsson, M., Jencks, J., Johnston, G., Lamarche, G., Mayer, L., Millar, D., Pedersen, T.H., Picard, K., Reitz, A., Schmitt, T., Visbeck, M., Weatherall, P. and Wigley, R. (2019) Seafloor Mapping-The Challenge of a Truly Global Ocean Bathymetry. Frontiers in Marine Science, 6, 283.

https://doi.org/10.3389/fmars.2019.00283

[51] Wright, D.J. and Heyman, W.D. (2008) Introduction to the Special Issue: Marine and Coastal GIs for Geomorphology, Habitat Mapping, and Marine Reserves. Marine Geodesy, 31, 223-230. https://doi.org/10.1080/01490410802466306 